\title{
Ageing in a changing place: a qualitative study of neighbourhood exclusion
}

\author{
Lena Dahlberg ${ }^{1,2 *}$ \\ ${ }^{1}$ School of Education, Health and Social Studies, Dalarna University, Falun, Sweden and ${ }^{2}$ Aging Research \\ Center, Karolinska Institutet \& Stockholm University, Solna, Sweden \\ *Email: ldh@du.se
}

(Accepted 19 March 2019; first published online 3 May 2019)

\begin{abstract}
An inclusive neighbourhood is a key facilitator enabling older adults to age in place. Neighbourhoods have been identified as a dimension of social exclusion important to older adults, and it has been argued that older adults are particularly vulnerable to neighbourhood change. The aim of this study was to explore older adults' experiences of neighbourhood exclusion within the context of neighbourhood change. Focus groups were undertaken in the urban and rural areas of a metropolitan borough in England involving a total of 41 older adults, with data analysed via thematic analysis. Urban areas in the borough studied have transformed following the closure of the mining industry, with a high level of deprivation in many areas, while some rural areas have undergone gentrification. Within the context of structural neighbourhood change, four themes were identified: community cohesion, political agency, feelings of safety and the physical environment. The themes were interlinked, which calls for collaboration across traditional lines of professional responsibility, and for research that encompasses different aspects of neighbourhood exclusion. This study contributes with knowledge on older adults' experiences of exclusion, including novel findings on the importance of political agency and collective memory, and identifies actions to combat exclusion. An active involvement of older adults in the development of initiatives to tackle social exclusion is recommended.
\end{abstract}

Keywords: older adults; social exclusion; social integration; neighbourhood; community; political agency; crime; environment

\section{Introduction}

At the European Union (EU) level and within many individual European countries, there are two parallel trends in social policy concerning older adults living in the community. Firstly, there is an aim that people should 'age in place', that is, to remain in their ordinary home and neighbourhood even when faced with increased frailty (Genet et al., 2011). This policy is based on the argument that older adults are able to remain more independent and socially integrated by ageing in 
environments to which they are accustomed (Rowles, 1993; Wiles et al., 2012), and that neighbourhoods have an important role in older adults' wellbeing and sense of belonging (Lager et al., 2013). For older adults to be able to age in place, there is a need for age-friendly communities facilitating their inclusion in society (World Health Organization, 2007). However, changing neighbourhoods can challenge social integration and the sense of belonging, and may increase the risk of social exclusion among older adults (Lager et al., 2013).

Secondly, there is a concern about social exclusion. Combating social exclusion is a key target in European and international policy (Popay et al., 2008; United Nations, 2010; European Commission, 2013), and there is evidence that social exclusion is associated with poor health and quality of life, and with mortality (Becker and Boreham, 2009; Saito et al., 2012; Sacker et al., 2017; Dahlberg and McKee, 2018). Social exclusion has been defined by the EU as a 'process whereby certain individuals are pushed to the edge of society and prevented from participating fully' (Council of European Union, 2004: 8). For older adults, exclusion from their neighbourhood has been identified as an important dimension of social exclusion. This article reports findings on older adults' experiences of exclusion from their neighbourhood, based on focus groups with older adults living in postindustrial and rural communities in a borough in England.

\section{Social exclusion}

There is no single definition of social exclusion. Common to many definitions is, though, that social exclusion is a process rather than a static condition and that it is multi-dimensional, that is, that disadvantages in one area of life are linked to disadvantages in other areas of life (Walsh et al., 2017). Dimensions covered by the concept of social exclusion include, for example, production activity, financial activities, social relations, social activity and political/civic activity (for an overview, see Levitas et al., 2007). Generally, there has been a strong research focus on production activity, that is, exclusion from the labour market. This form of exclusion is, however, of limited relevance for retired older adults, a group identified as particularly at risk of exclusion (European Commission, 2011). Instead, the significance of exclusion from the neighbourhood has been proposed (Scharf et al., 2005) and it has been shown that such exclusion is negatively associated with health and wellbeing (Dahlberg and McKee, 2018).

An argument for the significance of neighbourhoods for older adults is that they may be more vulnerable than younger people to changes in their neighbourhood. This assumption is based on the fact that retired older adults, compared to younger people, tend to spend more time at home or in their immediate neighbourhood; are more likely to have resided a long time in the same neighbourhood and have strong emotional investments in their surrounding area; and, as they age, increasingly rely on neighbourhood relationships for support (see Buffel et al., 2013).

Research on exclusion from neighbourhoods has covered subjective experiences in terms of social and relational aspects of space, such as feelings of connection to the neighbourhood, satisfaction with the neighbourhood, feelings of security and trust in people living in the neighbourhood, and has also covered more physical aspects and objective features of the environment, such as the built environment, 
services and transport (Van Regenmortel et al., 2016; Walsh et al., 2017). However, Peace et al. (2007: 233) have noted: 'Although there is a clear consensus that both physical and social environments are closely interwoven, ageing research has tended to separate both of these "worlds"', and argue that this is due to pragmatics, as it is convenient to separate the professional world into those whose work concerns social environments or physical environments, respectively.

Many of today's older adults live in neighbourhoods that have undergone or are undergoing change. Neighbourhood changes involve increasing deprivation, for example, in post-industrial, urban communities. Socio-economic inequalities across British neighbourhoods are considerable and reflected in an almost three times higher risk of premature mortality in deprived than affluent areas, particularly old industrial and urban areas (Plumper et al., 2018). Rural neighbourhoods are also being transformed. While there is outmigration of inhabitants in some rural areas, there is gentrification in other rural areas; that is, an 'invasion of previously working-class neighbourhoods by middle or upper-income groups and the subsequent displacement of many of the original residents' (Burns et al., 2012: 2).

Rapid neighbourhood change can influence the attachment to and inclusion in the area, and the desire to 'age in place' may be problematic as local communities become 'less resourceful, accessible and meaningful after kith and kin have gone' (Gilleard and Higgs, 2006: 128). Yet, it is unclear how neighbourhood changes affect older adults who age in place (Burns et al., 2012). The aim of this article is to explore different aspects of older adults' experiences of exclusion from the neighbourhood in the context of neighbourhood change.

\section{Methods}

\section{Study setting}

This study was undertaken in a metropolitan borough in England, United Kingdom (UK). It has a population of approximately 231,000 , of whom 23.7 per cent are 65 years or older, about the same proportion as for England as a whole. The population is predominantly White British (97.9\%; Office for National Statistics 2011).

The borough studied incorporates a number of communities which used to be governed by their own councils. Following the Local Government Act 1972, surrounding towns and villages were adopted as part of the same borough. Geographically, this borough falls into two broad areas: the west is mainly rural and the east is mainly urban and former heavy-industrial. Traditionally, the urban communities were built around the coal-mining industry. At the beginning of the 1980s, this industry employed over 20 per cent of all workers in this borough, and over 40 per cent of the workers in some of its areas (Office for National Statistics 1981). The last of the collieries closed in the mid-1990s. They have not been replaced by other manufacturing firms, leaving this borough deprived in many respects, including material needs, skills levels and access to services (Noble et al., 2009).

\section{Design, participants and procedure}

Focus groups were undertaken to collect qualitative data in each of the five districts of the borough. In addition, a pilot focus group was held. 
Focus group participants were mainly recruited via networks established by Age Concern (a third-sector organisation providing support and activities for older adults, now called Age UK), although the participants' levels of engagement with Age Concern varied. All individuals recruited within a given district formed the membership of a focus group, with each of the five groups meeting on two separate occasions in 2007. The focus groups included between three and ten participants, with a total of 41 participants. The majority (85\%) of the participants were between 65 and 85 years. The majority (73\%) of participants were women.

The focus group discussions were guided by a topic schedule which included the following themes: the neighbourhood, social activities, social network, factors enabling/preventing social participation, loneliness, services, transport, age discrimination, quality of life and change in individual circumstances. Here, findings related to the neighbourhood dimension of social exclusion are presented.

\section{Data analysis}

All discussions were digitally recorded and transcribed in full. Data were analysed via thematic analysis using Framework Analysis (Ritchie and Spencer, 1994), which follows a five-stage process:

(1) Familiarisation: reading through the transcripts several times to get an overview of the richness, depth and diversity of material gathered.

(2) Identification of the thematic framework: identifying key issues, concepts and themes according to which the data can be examined by combining a priori issues derived from key concepts in the literature and the aims of the study (deductive analysis) with categories derived from the data (inductive analysis).

(3) Indexing: a process of applying the thematic framework to the data, using codes to identify specific pieces of data that correspond with differing themes (in other qualitative analysis approaches often called 'coding').

(4) Charting: creating charts with headings and sub-headings drawn from the thematic framework.

(5) Mapping and interpretation: pulling together key characteristics of the data, and mapping and interpreting the data-set as a whole.

Quotes from the focus group discussions have been slightly edited to make them easier to read and understand. The names of the borough and its districts as well as names of participants, persons mentioned and street names have been anonymised.

\section{Results}

Neighbourhood change was discussed in the focus groups and forms the context of this study. The results section starts with a presentation of the participants' views on structural neighbourhood change, then the themes emerging from the data are presented. Four themes were identified: community cohesion, political agency, feelings of safety and the physical environment. As evident below, all these themes were related to neighbourhood change at the same time as they were interlinked. 
Table 1. Themes and sub-themes

\begin{tabular}{ll}
\hline Themes & Sub-themes \\
\hline Community cohesion & $\begin{array}{l}\partial \text { Social integration } \\
\partial \text { Trust }\end{array}$ \\
\hline Political agency & $\begin{array}{l}\partial \text { Neighbourhood identity } \\
\partial \text { Local government representation }\end{array}$ \\
\hline Feelings of safety & $\begin{array}{l}\partial \text { Crime/fear of crime } \\
\partial \text { Generational divide }\end{array}$ \\
\hline Physical environment & $\begin{array}{l}\partial \text { Obstacles in built environment } \\
\partial \text { General ignorance } \\
\end{array}$ \\
\hline
\end{tabular}

Each theme included two or three sub-themes. An overview of themes and subthemes is presented in Table 1.

\section{Structural neighbourhood change: 'It was a different area altogether'}

Many focus group participants had lived in their community for much of, if not all, their lives, and had grown up in areas where the mining industry was the main local employer. The industry offered a social support structure with welfare schemes and events such as parades for families and the Miners Welfare Clubs.

I was born in this area, in a mining village. In the mining villages the owners organised miners' welfare schemes. They always had a bandstand and there was always a band playing every Sunday.

The focus group participants held mixed views on the closure of the mines and the neighbourhood changes that followed. Although the decline of the mining industry meant that many workers had been made redundant, the closure of the mines was sometimes viewed in a positive light, as it was felt that this had led to a better quality of life, especially in relation to health and wellbeing, and in relation to the physical environment:

It had to be a blessing when they closed the pits. People actually started living. I mean a lot of my mates were in pit, I wouldn't go in. They used to sit here and they're coughing ... and they couldn't breathe properly. Oh, that weren't a life.

I mean nowadays the air is clean, in them days you've got big chimneys belching smoke out.

Parallel to these kinds of observations, there was a pride in the local mining history, here illustrated by the following comments: 
At the front of the town hall, there is going to be a statue of a miner with every name of each pit that has ever been in [the borough] and around it. That should be good.

There used to be a demonstration with the miners, parades with the miners holding the banners of different pits. There used to be a lot of pits around [the city] and since the pits closed down all that has stopped.

For different reasons, the rural part of the borough has also undergone transitions. A quote from a participant living in a rural area can serve as an illustration of changes in terms of gentrification. It also illustrates how neighbourhood change was sometimes blamed on people moving into the area from outside without vested interest in the area:

[The district] was a small community. It's now growing into a town. It's been spoilt. People who have lived in this community a long time, the families from here, they can't live here because they can't afford houses, so they're being driven out and people are coming in here, buying up properties.

When discussing neighbourhood change, one participant said: 'it was a wonderful area socially, politically' and continued 'now it's all gone', and it was argued that in those days the borough was a 'different area altogether'.

\section{Community cohesion: 'You don't see the neighbours'}

There was an agreement that neighbourhood changes have consequences for community cohesion, which was discussed in terms of two sub-themes: social integration and trust.

Participants remembered that before the closure of the mines, people would help one another in a way they 'wouldn't dream of now, no way'.

We were more of a community then. It's a long time ago, wasn't it? I mean, it may have changed now, but [then] people would take your washing in if it rains.

I can remember as a child, neighbours talked and if a neighbour was ill then you were sent up with a plate of dinner and things like that. That's all gone.

Participants emphasised the close relationships between neighbours, a closeness that was sometimes based on kinship:

When I first got married we lived in a row of about eight little terraced houses and I think there were two of us out of the eight houses who weren't related, everybody else was related.

In some areas participants reported on social isolation where they rarely met their neighbours, because neighbours 'don't want to mix' or are 'out at work to pay their mortgages'. They noted that 'mothers work as well in this day and age' 
and that there was 'nobody on streets'; and that younger people led busy work lives that took them away from the neighbourhood during the day, with negative effects on community cohesion:

It's dead quiet. I mean school children go past but that's it. You don't see the neighbours [...] Occasionally they come out and cut their grass and then you see them.

Participants said that talking over the garden fence was a phenomenon of the past and that interaction between neighbours was limited. The 'neighbourliness' and trust were gone, doors were locked and 'everybody has become isolated within their own environment'. In one focus group, participants discussed the fact that they did not like locking their doors, as this made them feel like 'insulars'.

The weakened community spirit was not unique to post-industrial communities. Changes in rural areas included gentrification, mentioned above, with people moving into the areas from outside. It was argued that this transformation of rural areas had contributed to an undermined community spirit. This sceptical view on people from outside the borough was mirrored in the experience of one participant who had moved to the borough relatively recently and found it difficult to integrate:

We have only been here six years, we're relative newcomers and people still don't speak to us because we are from the outside!

However, not all participants shared this experience. Some, who had not lived all their lives in their community, remarked on the friendliness of the local people and how they had found it easy to integrate with the locals:

I've found people here extremely friendly, very, very friendly. On the bus you know, gentlemen are just the same, they'll strike up a conversation. I've lived in various places but this is one of the most friendly places I've ever been to.

However, despite a perceived decline in community spirit, participants said that they 'love living here', and some participants felt that there was still a strong community spirit and social integration in their local area.

\section{Political agency: 'They are supposed to be representing us'}

The borough is a diverse area that incorporates both urban and rural communities, each of which has their own strong identity. A central theme in discussions concerned political aspects of the neighbourhood. Two related sub-themes emerged from the data: neighbourhood identity and local government representation.

Neighbourhood identity was rooted in historical political borders. Despite the changed governance by which the borough council took control over constituent surrounding towns and villages, participants' loyalties lay with their local areas, perhaps most clearly expressed here: 
This altered since we weren't called [the old county name] anymore, because I will not have it that I live in [the new county], I won't have it, I had [the old county name] under my chair bottom at school and it's still on my bottom.

The changed governance was a topic raised in most focus groups. For example, a district that used to be part of another council was described as a 'lovely' and 'wonderful' council. There were a number of indications of political aspects of neighbourhood exclusion in the present study, including a lack of political agency and people who did not feel represented by their politicians: 'they are supposed to be representing us but they don't'. It was noted that their area was now just a small part in a larger district:

The problem is that when they stand to say something they don't get a chance or they get out-voted. When we had our own council, the council made a decision for our area. If they wanted to build this road or build something else, it happened. Now it has to go to the borough council and it's a big bugbear.

Participants argued that the centralised government has had practical implications. They experienced that they used to have a council of their own and that they could go down to the council office to get things done. Today, a participant claimed, it takes least two years to get smashed railings replaced: 'I'm still waiting and I've been waiting two years.'

It was also argued that the changed governance had led to cutbacks in their areas, for example, regarding maintenance of roads, pavements and lawns, as well as threats to cut back local facilities such as the fire service, police resources, an older adults' centre and a town hall. One participant concluded: 'this council, they're gradually closing everything'. In addition, the participants noted a competition between different areas of the borough. One participant said 'we've got postcode politics' and continued:

Grants are given out to different areas, well good luck to them ... If [the district] puts a proposal forward or you try to do something you're against a brick wall.

Participants felt let down by their politicians and regretted the consequences for their communities. One of them even argued that local and national politicians had 'brought about the destruction of good law-abiding communities'. Another participant said:

It boils down to that people no longer trust the two organisations that gave us trust. One is the council and the other is the police. The people, this community, no longer have any trust in either of them.

\section{Feelings of safety: 'You can't go nowhere'}

This theme included two sub-themes: crime/fear of crime and generational divide. Within the context of neighbourhood change, participants from across different areas of the borough noted that their area was deteriorating. For example, participants said their local area was 'going downhill', 'is rough' and 'far worse off in many, many ways than what it was'. Such neighbourhood changes had impacted on the social order, here described by one of the participants: 
[The industry building] became derelict and there were drug addicts in it and vandalism. You could hear them smashing the windows. That was quite scary and my car got broken into a few times. It was really difficult.

Impact on social order was further revealed as participants were frightened to go out at night. One of them explained that 'it's not safe to go out at night, because you get mugged', while another participant said:

We no longer go out at night because it's not safe. So we've cut our activities down to where we can go in the afternoon, usually anyway, and in the morning. We go to church on a Sunday morning, so that is one thing, but we've cut out going out at night.

Participants thought that crime had become more common and one participant said that 20 years ago she used to walk down to the village for an evening meeting, something that she would not dare to do any longer. Fear of crime was seen as linked to age. For example, one participant explained: 'we can't defend ourselves, at one time we could hit them, but we can't now'. A lack of trust in the police contributed further to feelings of unsafety. One participant had a brick thrown through his window in the middle of the night, but when he called the police, they did not arrive until after 10 o'clock in the morning the following day.

There was also a generational divide, with a consensus among the participants that there were some younger people who caused problems and intimidated people by gathering in groups. Younger people were named as a key source of fear, which made older adults stay indoors at night:

I can't go out at night because there are that many kids on street and especially when it's dark you can't go nowhere. When dark nights come, I mean it's dark at four, you never move.

A lot of young people think that old people have a lot of money, so they're going to have a share. Why work if they get money off old people?

On top of the fear that younger people would commit crimes, the presence of younger people in groups in itself was intimidating for some older adults:

Because we get gangs of big lads playing in the street, you know, just congregating under the lamps, not doing anything wrong, they're congregating, shouting to one another, swearing of course.

Although experiences and fear of crime were often linked to younger people, it was acknowledged in most of the focus groups that it was a minority of younger people who were committing crime or demonstrating anti-social behaviour. Also, in one area, neighbours had given each other their phone numbers and arranged an informal neighbourhood watch, that is, crime prevention organised by people living in a local area. 


\section{Physical environment: 'Whole communities being stranded'}

The physical environment of neighbourhoods can exclude older adults from social participation, social interaction and services. This theme included different aspects of the physical environment, including three sub-themes: obstacles in built environment, a general ignorance (of the needs of people with functional limitations making it more difficult to manoeuvre in the environment) and public transport.

Regarding the built environment, participants discussed barriers such as spring doors, narrow gates and concrete blocks to prevent motorcycles entering walkways. Obstacles in the physical environment were generally noted by people with physical impairments, especially those using electric scooters or wheelchairs. One participant using a scooter noted: 'all around this estate there are fences where you can't get through'. However, participants without impairments also found difficulties in the physical environment in their local area. Barriers to overcome included uneven road surfaces and hilly terrain:

I can't walk on my pavement from the bus stop at top of [the road] ... I have to walk in the road when I'm getting the bus because the pavement is not fit to walk on.

It depends on your walking abilities as well ... I know I fancied going to that computer activity, but I thought there's no way I can walk up [the road].

Bad weather with snowy or icy conditions made accessibility even worse, and fear of falling stopped some participants from going out:

Years ago they used to come down your street with a wagon and throw a little bit [of grit] on path. We don't get anything like that now. If the pathway is bad the pathway is bad, you take your chance. That does keep you in, that definitely keeps people inside.

Central to the sub-theme of general ignorance was a feeling among participants that accessibility became unnecessarily difficult due to the general public's lack of awareness about the difficulties faced by disabled older adults. This manifested in behaviours such as inconsiderate parking of cars and bins placed on the pavements.

One thing that I have found, though, is the number of people that'll go and park in a designated disabled area. No card out or anything.

The bane of my life has got to be Tuesdays. I can't get out of the house on Tuesdays. It is bin day, wheelie bins. The bin men are allowed to chuck them anywhere. The number of times I phone them up complaining ... Why don't they put them back?

It should be noted, though, that some participants felt that they were offered additional courtesy because of their visible impairments:

On the [walking] sticks, people can't do enough for me. If I go shopping, they'll come and say 'can I help put your things in car?' I went to theatre one 
Saturday night and I wanted to cross the road from theatre to car park, and a young fellow came and said 'I'll stop them' and he got in middle of road, and stopped the cars until I got across the road.

Public transport, addressed in the third sub-theme, can be a means to negotiate the physical environment, and this issue was extensively discussed. Participants argued that transport was related to social exclusion, as transport can both facilitate and prohibit participation in social activities and access to services. For participants who relied on public transport, two major problems were identified. Firstly, there were problems with availability of buses and bus routes. For example, it was said: 'in my area, they [buses] used to come every half hour, there are three a day now' and 'we've got free bus pass, but if there's no buses...' Participants stated that bus routes had been withdrawn so they could no longer get to the places they wanted to visit, or they had to take convoluted routes, often involving several bus changes. Many people felt that they were restricted in where they could go and which services they could access, and even if they reached their destination, participants were not sure whether they would be able to get back. One focus group participant argued: 'Oh, there can't be a social life if there are no means to get there and get back.'

Secondly, some participants had experienced problems with some bus drivers whom they felt had treated them differently because of their age. Negative behaviour surfaced particularly in relation to participants' bus travel concessions, commonly provided outside peak travel times to older adults in the UK, and their need to access the buses conveniently. For instance, one participant claimed that all bus drivers called older adults 'too earlies', referring to their perception that older adults tended to arrive at the bus stop in advance of the bus concession period.

Experiences of transport as a means to inclusion depended on whether or not participants relied on public transport, but also on which local area they lived in. There were general problems with regard to public transport in the rural areas of the borough, as noted by one participant: 'in the rural areas, there just aren't the buses to get out'. In several focus groups, people talked about being 'stuck' and 'stranded'. It was argued that lack of public transport not only had implications for the individuals, but also at neighbourhood level:

You're not just getting the isolated family, the isolated person at home, me stranded, you're getting whole communities being stranded.

Furthermore, reliance on public transport and the fact that buses were less frequent at night were compounded by fear of going out at night and, thus, with the theme 'feelings of safety'.

But there are a lot of people who would like to go out in the evening, just for an hour or two to meet up, but there is nowhere to go and apart from that it's frightening for old people to go out at night. If I didn't have the car I would never go out at night. 


\section{Discussion}

It has been argued that familiar physical and social environments enable older adults to remain independent and socially integrated (Rowles, 1993; Wiles et al., 2012). However, this 'idealised notion of ageing in place' does not always correspond with the experiences of older adults, as it is based on an assumption that the place is static (Lager et al., 2013: 54). Based on focus groups with older adults in a borough in England, this article aimed to explore older adults' experiences of exclusion from their neighbourhood in the context of neighbourhood change.

\section{Relating to neighbourhood change}

This study found that some older residents found it difficult to connect to people moving into the area from outside, particularly in gentrified rural areas. Neighbourhood change can, thus, have the consequence that older adults, despite long residency in an area, may feel socially isolated and excluded from their neighbourhood (Crisp, 2010). There may even be a sense that neighbourhood change can leave 'older people as isolated survivors of a previous generation' (Victor et al., 2009: 207).

Although the rural areas have changed with gentrification processes, the landscape is still largely rural. Transformation of living conditions has been more pronounced in the post-industrial urban communities, making these areas more deprived and placing older adults at higher risk of exclusion. The last coal mine in the borough closed down in the mid-1990s, but the importance of the industry remains part of the contemporary identity of older adults living in these areas. In previous research, older adults' perceptions of neighbourhood change has been discussed in terms of nostalgia. For example, Sim et al. (2012) report a sense of nostalgia over the loss of a strong sense of community and collective identity. However, telling stories of the past can go beyond nostalgia. Personal memories are always related to a wider social framework (Palmberger, 2016), and personal memories can become part of the collective (or social) memory of communities (Wheeler, 2014). Collective memories are reinforced in interaction with other members of the social group and can also be embedded in the material culture (Wheeler, 2014), for example, in a statue of a miner in front of the town hall. In some neighbourhoods people have personal stories that converge with formative national events, in the case of the studied borough the closure of a whole industry, and they can become representatives of a broader experience (Nettleingham, 2017).

It has been shown, though, that the collective memory of the past can become subject to a construction of a myth, such as a myth of a heroic miner, which can obscure a more complicated story of the miner (Gildart, 2009), and the interpretation of experiences involves not only sharing memories but also collectively silencing them (Palmberger, 2016). For example, research on neighbourhood exclusion has shown that people rarely referred to conflicts that may have occurred in the past (Buffel et al., 2013). Although conflicts was rarely mentioned in the present study, the pride associated with being part of a mining community sat alongside counter-arguments that demonstrated an appreciation of improved environmental conditions and an acknowledegment of hazardous working conditions in the past. 
This mirrors a previous study in which participants frequently referred to the tough, dangerous working conditions of the mines and the difficult lives that the mine workers and their families must have endured' (Wheeler, 2014: 28).

\section{Neighbourhood exclusion}

Within the broader context of neighbourhood change, four themes emerged from the data: community cohesion, political agency, feelings of safety and physical environment.

Community cohesion concerned social integration and trust. While some participants experienced a strong community spirit in their neighbourhood, others said that they rarely met their neighbours, mainly because the neighbours were working and did not spend much time in the neighbourhood. Today, it is not uncommon for people in the coalfield areas of this borough to commute for work to neighbouring areas, other urban centres and newer employment zones (Gore and Fothergill, 2007). Also, in the first half of the 20th century, life in urban neighbourhoods was often interconnected by kinship and integrated across generations, especially in traditional working-class neighbourhoods, but this kind of community life gradually changed with the increased female participation and changed migration patterns (Gilleard and Higgs, 2006). Findings on perceived lost 'neighbourliness' and lack of interaction between neighbours echo those of Scharf and Bartlam (2008). Their interviewees had a positive view of the past contrasted with a loss of intimacy in current times.

Yet, some participants in the present study stated that the community spirit was still strong and that it could be hard to become included if you had moved into the area. Participants in previous research share such experiences and describe difficulties in integrating, pointing towards the fact that social integration may not be accessible for all (Walsh et al., 2012).

The theme political agency concerned neighbourhood identity and local government representation. Participants had strong attachments to the local area rooted in historical political borders and there was a general scepticism towards the centralised metropolitan borough council. Some participants did not feel represented by their politicians and argued that their local area was disadvantaged in borough politics, for example through cutbacks in their local area and threats to close down local facilities and services. There was a feeling of alienation from the local decisionmaking process and low (vertical) trust in politicians and also in the police (see e.g. Szreter and Woolcock, 2004).

Civic engagement and involvement in decision-making are central aspects of social exclusion. This dimension of exclusion, often called civic exclusion, has traditionally been studied in terms of, for example, involvement in voluntary organisations or voting at political elections (Burchardt et al., 2002; Barnes et al., 2006). However, the neighbourhood in terms of borders of constituencies and political representation has rarely been explored in social exclusion research and there is a potential for further research to address the intersection of civic exclusion and neighbourhood exclusion. This study shows that older adults can be strongly emotionally attached to the neighbourhood, at the same time as they experience a lack of political agency. Interestingly, there is evidence that insufficient opportunities for political participation contributes to feelings of unsafety (De Donder et al., 2012). 
Crime and fear of crime were central to the theme feelings of safety, as was the generational divide. Participants reported that they avoided going out at night due to fear of crime and feeling vulnerable, and some of the fear was attributed to antisocial behaviour among younger people. Fear of crime has been identified as one of the most prevalent risk markers for social exclusion, with nearly a third of older adults in England experiencing fear of crime (Becker and Boreham, 2009). Previous research has shown that fear of becoming a victim of crime is associated with low levels of neighbourhood involvement (De Donder et al., 2012), and that a perceived vulnerability tends to reduce older adults' levels of activity, especially after dark (e.g. McKee and Milner, 2000; Waterhouse and Angley, 2005).

The theme physical environment partly concerned the built environment, where the participants identified a number of obstacles that made it difficult for them to negotiate the environment. Obstacles in the physical environment have previously been noted in relation to neighbourhood exclusion. For example, Smith (2009: 43) has discussed hills and poorly maintained road surfaces as 'daily hassles' of the environment (see also Grenier and Guberman, 2009). Obstacles of the physical environment and older adults' capacity to negotiate such obstacles have in some previous research also been discussed as person-environment fit (see e.g. Clarke and Nieuwenhuijsen, 2009).

Obstacles can arise from initial design of the physical environment or from poor maintenance, but they can also be exacerbated by characteristics of people occupying the spaces. Participants experienced a general ignorance of the needs of older adults with functional limitations, exemplified by poor parking or bins left on the pavement. This lack of awareness of older adults' needs is related to the discussion on ageism. Dean (2009) has identified three forms of discrimination: overt and intentional; disguised but deliberate; and unintentional but adverse. Inconsiderate or ignorant behaviour can be seen as an example of unintentional but adverse ageism.

Appropriate public transport can help older adults in negotiating the physical environment. However, participants argued that sometimes transport prohibited participation in social activities and access to services. Barriers mentioned included poor availability of buses and bus routes; unreliable services; and bus drivers' negative attitudes towards older adults. In a study of social exclusion in rural areas (Scharf and Bartlam, 2008), both obstacles in the physical environment and lack of transport were discussed in relation to exclusion from services, and transport was a key concern when accessing more distant services and influenced social engagement ( $c f$. Warburton et al., 2017). Two in five older adults in rural areas experience difficulties in accessing services, and transport has been identified as the primary issue facing older adults in rural areas (see Noble et al., 2009). In the present study, unreliable and infrequent public transport, especially when coupled with fear of crime, resulted in some older adults avoiding going out at night.

Themes identified in this study represent different aspects of neighbourhood exclusion, but they are also interlinked. For example, objects in the physical environment, such as vandalised or derelict buildings or broken fences, were related to community cohesion, social integration, safety and political agency; and feelings of unsafety and generational divide were related to community cohesion and lack of political agency. Interrelations and overlaps across themes demonstrate the complexity of social exclusion experiences, even when the primary focus is on only 
one dimension of exclusion, in this case neighbourhood exclusion. The interlinks across themes also point towards the importance of studying intersections of, for example, the social and physical environment (cf. Victor et al., 2009; Cramm et al., 2018) and the strength of the multi-dimensional framework of social exclusion. Broad approaches to the research of exclusion can also accommodate the study of accumulation of exclusion across different dimensions and over time (Becker and Boreham, 2009; Heap et al., 2017; Van Regenmortel et al., 2018).

\section{Implications for research, policy and practice}

There was a general perception among participants that the community spirit had been undermined during their lifetime. Community cohesion, social integration and trust is related to feelings of safety and to intergenerational relationships. As people age, they become more dependent on support from people in the neighbourhood and are more vulnerable to crime. Therefore, in order to increase the potential for older adults to age in place, an area of priority for policy and practice is to support neighbourhood organisations and local authorities in fostering cohesion between older adults and across generations (cf. Walsh et al., 2012), and also to address actively issues of crime and anti-social behaviour in, for example, initiatives promoting neighbourhood regeneration. This is in line with recommendations from a recent review, in which the importance of reciprocity, meaningful activities and respect for individual differences in social needs are also emphasised (ten Bruggencate et al., 2018).

Focus also needs to be directed towards the political environment and local development. This is important both in relation to community cohesion and local identity. It is likely that the political agency becomes particularly vulnerable in neighbourhoods undergoing radical changes. Therefore, this dimension may have become more observable in this study than it would have been in a study of a more stable neighbourhood. This study highlights how loyal people can be towards previous political-administrative units and that changes of borders can lead to mistrust of politics and politicians. This calls for action among politicians to work with building trust, meeting citizens and giving them an opportunity to engage in the political process, for example, via consultation on topics with relevance for the neighbourhood.

In addition, designing out obstacles in the physical environment, such as poor lighting, poor road surfaces and fences preventing access for people with functional limitations, may not only facilitate social inclusion but may also reduce the risk of falls among older adults and positively affect their level of physical activity (Chaudhury et al., 2012). It has been argued that making relatively minor adjustments to buildings at the design stage is far less costly than trying to make improvements afterwards, and also that 'inclusive' environments benefit all citizens (United Nations, 2002). When trying to live a socially active and independent life as an older adult, appropriate and efficient public transport is equally important. Both the built environment and access to transport are central for neighbourhood inclusion and the potential to age in place.

Enabling and supportive environments for older adults is a priority of the World Health Organization's initiative Age-friendly Communities (World Health 
Organization, 2007). This initiative includes, for example, opportunities for social participation and civic engagement, and meeting basic needs such as safe housing. Such initiatives have to meet challenges posed by changing characteristics of communities and the impact such changes can have in terms of social exclusion of older adults. However, a general lack of research on best practice to make communities more age-friendly and on the effect of such initiatives on communities and individuals has been noted (Lehning and Greenfield, 2017).

This study reveals differences across urban and rural areas. Generally, urban areas had undergone changes in the direction of deprivation and there were issues related to, for example, safety, whereas participants in rural areas faced problems in terms of, for example, insufficient public transport. Crucial to any intervention to combat exclusion from neighbourhoods is to target the conditions and needs of each particular area.

Intersections and overlaps of themes and policy areas imply that policy and practice need to collaborate across organisations and professions, and work across traditional lines of responsibilities when addressing social exclusion among older adults. Previous research suggests that informal practices, in which people work across system boundaries of state, private, voluntary and family/friend spheres, have the potential to strengthen the capacity of communities to address social exclusion among older adults (Walsh et al., 2014).

\section{Study strengths and limitations}

The nature of focus groups and their requirement for active involvement led to a concern that few of the participants would have first-hand experiences of social exclusion. Previously it has been noted that people at risk of social exclusion are not represented in research studies (Levitas et al., 2007). In this study, participants were recruited mainly via an established organisation, even though their level of engagement with activities arranged by this organisation varied. Given this, it may be surprising that several of the participants in the present study had experienced some form of social exclusion. Many of them were also able to communicate the views of friends or neighbours with such experiences.

In some instances, participants were known to each other. As social exclusion may be a sensitive topic, it could be anticipated that the participants would not be prepared to share their views and experiences. At times it was difficult for some participants to discuss their feelings, but overall the majority of participants were very willing to express their views openly.

A strength of this study is that it provides older adults' views on neighbourhood exclusion in the context of changing neighbourhoods, both urban and rural. Still, more research is needed in order to determine to what extent these findings are representative for the larger population of older adults, and also to examine prevalence, causes and consequences of social exclusion in old age as well as how different dimensions of social exclusion are interrelated.

\section{Conclusions}

This study showed that neighbourhood change is part of personal as well as collective memories of older residents, and that social exclusion is affected by 
neighbourhood change and manifested in the neighbourhood in different ways. This study also revealed the complexity of social exclusion and identified important aspects of neighbourhood exclusion, that is, community cohesion, political agency, feelings of safety and the physical environment. These aspects of neighbourhood exclusion were interlinked. This calls for collaboration across established system boundaries, but also for research that considers both social and physical aspects of neighbourhood exclusion. More explicitly than most research on social exclusion, this study highlights the importance of political agency for older adults' inclusion in and attachment to the neighbourhood. Neighbourhood change and political representation are central aspects of how included older adults feel in the neighbourhood, and this needs to be considered in future social exclusion research involving older adults as well as in policy and practice interventions. Knowledge on the experiences of older adults and their active involvement in interventions are crucial for the development of effective policy to combat social exclusion and to enable older adults to age in place.

Author ORCIDs. (D) Lena Dahlberg, 0000-0002-7685-3216

Acknowledgements. I am very grateful to Dr Tamsin Bowers-Brown at the University of Derby, who contributed to this research by undertaking focus groups, being involved in data analysis and commenting on draft versions of the manuscript. I am also grateful to colleagues in the Department of Social Work at Dalarna University and to two anonymous reviewers for their comments on an earlier draft of the manuscript.

Financial support. The Barnsley Social Exclusion in Old Age Study, undertaken in collaboration between Age Concern Barnsley and Sheffield Hallam University, was supported by The Big Lottery Fund, Research Grant Programme (grant number RG/1/010166820). The funding body had no role in design, execution, analysis and interpretation of data, or writing of the article.

Conflict of interest. The author declares no conflicts of interest.

Ethical standards. Ethical approval was provided by Sheffield Hallam University Faculty Research Ethics Committee, Faculty of Development and Society.

\section{References}

Barnes M, Blom A, Cox K, Lessof C and Walker A (2006) The Social Exclusion of Older People: Evidence from the First Wave of the English Longitudinal Study of Ageing (ELSA): Final Report. Available at http:// www.ifs.org.uk/docs/odpm_social_exclusion.pdf.

Becker E and Boreham R (2009) Understanding the Risks of Social Exclusion Across the Life Course: Older Age. London: Cabinet Office and National Centre for Social Research.

Buffel T, Phillipson C and Scharf T (2013) Experiences of neighbourhood exclusion and inclusion among older people living in deprived inner-city areas in Belgium and England. Ageing \& Society 33, 89-109.

Burchardt T, Le Grand J and Piachaud D (2002) Introduction. In Hills J, Le Grand J and Piachaud D (eds), Understanding Social Exclusion. Oxford: Oxford University Press, pp. 1-12.

Burns VF, Lavoie JP and Rose D (2012) Revisiting the role of neighbourhood change in social exclusion and inclusion of older people. Journal of Aging Research 2012, 148287.

Chaudhury H, Mahmood A, Michael YL, Campo M and Hay K (2012) The influence of neighborhood residential density, physical and social environment on older adults' physical activity: an explorative study in two metropolitan areas. Journal of Aging Studies 26, 35-43.

Clarke P and Nieuwenhuijsen ER (2009) Environments for healthy ageing: a critical review. Maturitas 64, $14-19$. 
Council of European Union (2004) Joint Report by the Commission and the Council on Social Inclusion. Available at http://europa.eu.int/comm/employment_social/soc-prot/soc-incl/final_joint_inclusion_report_ 2003_en.pdf.

Cramm JM, van Dijk HM and Nieboer AP (2018) The creation of age-friendly environments is especially important to frail older people. Ageing \& Society 38, 700-720.

Crisp BT (2010) Belonging, connectedness and social exclusion. Social Inclusion 2, 123-132.

Dahlberg L and McKee KJ (2018) Social exclusion and well-being among older adults in rural and urban areas. Archives of Gerontology and Geriatrics 79, 176-184.

De Donder L, De Witte N, Buffel T, Dury S and Verte D (2012) Social capital and feelings of unsafety in later life: a study on the influence of social networks, place attachment, and civic participation on perceived safety in Belgium. Research on Aging 34, 425-448.

Dean M (2009) How social age trumped social class? In Cann P and Dean M (eds), Unequal Ageing. The Untold Story of Social Exclusion in Old Age. Bristol, UK: The Policy Press, pp. 1-23.

European Commission (2011) European Platform Against Poverty and Social Exclusion. Available at http://eur-lex.europa.eu/summary/EN/URISERV:em0046.

European Commission (2013) Europe 2020: A Strategy for European Union Growth. Available at http://eurlex.europa.eu/legal-content/EN/TXT/?uri=uriserv:em0028.

Genet N, Boerma WGW, Kringos DS, Bouman A, Francke AL, Fagerstrom C, Melchiorre MG, Greco C and Deville W (2011) Home care in Europe: a systematic literature review. BMC Health Services Research 11, 207.

Gildart K (2009) Mining memories: reading coalfield autobiographies. Labor History 50, 139-161.

Gilleard C and Higgs P (2006) Contexts of Ageing. Class, Cohort and Community. Cambridge: Polity Press.

Gore T and Fothergill S (2007) Cities and their hinterlands: how much do governance structures really matter? People, Place and Policy Online 1, 55-68.

Grenier AM and Guberman N (2009) Creating and sustaining disadvantage: the relevance of a social exclusion framework. Health and Social Care in the Community 17, 116-124.

Heap J, Fors S and Lennartsson C (2017) Coexisting disadvantages in later life: demographic and socioeconomic inequalities. Journal of Population Ageing 10, 247-267.

Lager D, Van Hoven B and Huigen PPP (2013) Dealing with change in old age: negotiating working-class belonging in a neighbourhood in the process of urban renewal in the Netherlands. Geoforum 50, 54-61.

Lehning AJ and Greenfield EA (2017) Research on age-friendly community initiatives: taking stock and moving forward. Journal of Housing for the Elderly 31, 178-192.

Levitas R, Pantazis C, Fahmy E, Gordon D, Lloyd E and Patsios D (2007) The Multi-dimensional Analysis of Social Exclusion. London: Social Exclusion Task Force.

McKee KJ and Milner C (2000) Health, fear of crime and psychosocial functioning in older people. Journal of Health Psychology 5, 473-486.

Nettleingham D (2017) Canonical generations and the British Left: the narrative construction of the miners' strike 1984-85. Sociology: The Journal of the British Sociological Association 51, 850-864.

Noble S, Smith T and Lally G (2009) Mapping the Level of Need: Assessing Social Exclusion Amongst Older People in Rural Areas. Report for Cabinet Office, Social Exclusion Task Force. Brighton, UK: Oxford Consultants for Social Inclusion.

Office for National Statistics (1981) 1981 census - special workplace statistics. Available at www.nomisweb. co.uk/datasets/sws81.

Office for National Statistics (2011) 2011 Census. Available at www.ons.gov.uk/census/2011census.

Palmberger M (2016) Introduction: Researching memory and generation. In Palmberger M (ed.), How Generations Remember. Conflicting Histories and Shared Memories in Post-war Bosnia and Herzegovina. London: Palgrave Macmillan, pp. 1-50.

Peace SM, Wahl H-W, Mollenkopf $\mathbf{H}$ and Oswald F (2007) Environment and ageing. In Bond J, Peace S, Dittmann-Kohli F and Westerhof GJ (eds), Ageing in Society: European Perspectives on Gerontology. London: Sage, pp. 209-234.

Plumper T, Laroze D and Neumayer E (2018) Regional inequalities in premature mortality in Great Britain. PLOS ONE 13, e0193488.

Popay J, Escorel S, Hernández M, Johnston H, Mathieson J and Rispel L (2008) Social Exclusion. Final Report to the WHO Commission on Social Determinants of Health from the Social Exclusion Knowledge 
Network. Available at http://www.who.int/social_determinants/knowledge_networks/final_reports/sekn_ final\%20report_042008.pdf.

Ritchie J and Spencer L (1994) Qualitative data analysis for applied policy research. In Bryman A and Burgess B (eds), Analyzing Qualitative Data. London: Routledge, pp. 173-194.

Rowles GD (1993) Evolving images of place in aging and 'aging in place'. Generations 17, 65-70.

Sacker A, Ross A, MacLeod CA, Netuveli G and Windle G (2017) Health and social exclusion in older age: evidence from Understanding Society, the UK household longitudinal study. Journal of Epidemiology and Community Health 71, 681-690.

Saito M, Kondo N, Kondo K, Ojima T and Hirai H (2012) Gender differences on the impacts of social exclusion on mortality among older Japanese: AGES cohort study. Social Science and Medicine 75, 940-945.

Scharf T and Bartlam B (2008) Ageing and social exclusion in rural communities. In Keating N (ed.), Rural Ageing. A Good Place to Grow Old? Bristol, UK: Policy Press, pp. 97-108

Scharf T, Phillipson C and Smith AE (2005) Social exclusion of older people in deprived urban communities of England. European Journal of Ageing 2, 76-87.

Sim J, Liddle J, Bernard M, Scharf T and Bartlam B (2012) Home from home? A mixed-methods study of relocation within a purpose-built retirement community. Journal of Housing for the Elderly 26, 372-394.

Smith AE (2009) Ageing in Urban Neighbourhoods. Place Attachment and Social Exclusion. Bristol, UK: The Policy Press.

Szreter S and Woolcock M (2004) Health by association? Social capital, social theory, and the political economy of public health. International Journal of Epidemiology 33, 650-667.

ten Bruggencate T, Luijkx KG and Sturm J (2018) Social needs of older people: a systematic literature review. Ageing \& Society 38, 1745-1770.

United Nations (2002) Madrid Action Plan on Ageing. Available at www.un.org/esa/socdev/ageing/waa/aconf-197-9b.htm.

United Nations (2010) Analysing and Measuring Social Inclusion in a Global Context. New York, NY: United Nations.

Walsh K, O'Shea E, Scharf T and Murray M (2012) Ageing in changing community contexts: cross-border perspectives from rural Ireland and Northern Ireland. Journal of Rural Studies 28, 347-357.

Walsh K, O'Shea E, Scharf T and Shucksmith M (2014) Exploring the impact of informal practices on social exclusion and age-friendliness for older people in rural communities. Journal of Community and Applied Social Psychology 24, 37-49.

Walsh K, Scharf T and Keating N (2017) Social exclusion of older persons: a scoping review and conceptual framework. European Journal of Ageing 14, 81-98.

Van Regenmortel S, De Donder L, Dury S, Smetcoren A-S, De Witte N and Verté D (2016) Social exclusion in later life: a systematic review of the literature. Journal of Population Ageing 9, 315-344.

Van Regenmortel S, De Donder L, Smetcoren A-S, Lambotte D, De Witte N and Verté D (2018) Accumulation of disadvantages: prevalence and categories of old-age social exclusion in Belgium. Social Indicators Research 140, 1173-1194.

Victor CR, Scambler S and Bond J (2009) The Social World of Older People. Understanding Loneliness and Social Isolation in Later Life. Maidenhead, UK: Open University Press.

Warburton J, Scharf T and Walsh K (2017) Flying under the radar? Risks of social exclusion for older people in rural communities in Australia, Ireland and Northern Ireland. Sociologia Ruralis 57, 459-480.

Waterhouse C and Angley P (2005) Social Exclusion Among Older People: A Preliminary Study from Inner-city Melbourne. Melbourne: Brotherhood of St Laurence.

Wheeler R (2014) Mining memories in a rural community: landscape, temporality and place identity. Journal of Rural Studies 36, 22-32.

Wiles JL, Leibing A, Guberman N, Reeve J and Allen RES (2012) The meaning of 'aging in place' to older people. Gerontologist 52, 357-366.

World Health Organization (2007) Global Age-friendly Cities: A Guide. Geneva: World Health Organization.

Cite this article: Dahlberg L (2020). Ageing in a changing place: a qualitative study of neighbourhood exclusion. Ageing \& Society 40, 2238-2256. https://doi.org/10.1017/S0144686X1900045X 